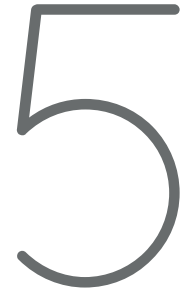

EVOLUCIÓN CULTURAL EN EL AZUAY PREHISTÓRICO:

Un Proyecto Arqueológico de la PUCE, SC.

Napoleón Almeida 


\section{EVOLUCIÓN CULTURAL EN EL AZUAY PREHISTÓRICO}

\section{INTRODUCCION}

En agosto de 1986 se iniciaron las actividades del proyecto arqueológico de la Pontificia Universidad Católica del Ecuador, Sede en Cuenca, gracias al convenio de cooperación celebrado entre este centro de estudios y el Consejo Nacional de Universidades y Escuelas Politécnicas del Ecuador (CONUEP). La institución que ejecuta el proyecto es el Decanato General de Investigaciones de la P.U.C.E. - S.C., al frente del cual se encuentra actualmente el Doctor Mario Jaramillo Paredes. Los analistas de este Decanato que colaboran en los trabajos son el Doctor Raúl Córdova León y el Licenciado Luis Araneda Alfero. Asesor del estudio es el Doctor Jorge Marcos Pinos, de la Escuela Superior Politécnica del Litoral, Guayaquil. El suscrito trabaja como investigador responsable.*

* Han colaborado como ayudantes permanentes los señores Galo Narváez, Mario Garzón E., Lauro Chacón y Diego Suárez.

Con este artículo no deseamos sino trazar un bosquejo de las estrategias a seguir para el estudio de la antigua historia azuaya y describir sumariamente lo que se ha cumplido en los cinco primeros meses de labores.

\section{LAS ESTRATEGIAS}

\subsection{Selección del tema}

Diferentes proyectos de investigación arqueológica han sido ejecutados durante el siglo presente en los Andes australes del Ecuador. Estudiosos de diferentes nacionalidades han establecido la secuencia cronológica de los lapsos cerámicos -y precerámicos- de la zona y han aislado los "tipos" de los utillajes correspondientes a las ocupaciones humanas establecidas hasta la etapa imperial. La secuencia temporal propuesta para el Azuay proviene básicamente de los reportes de arqueólogos extranjeros, quienes nos han legado una muy buena pauta introductoria a los estudios de prehistoria regional, por una parte, centrando no obstante el interés en la interpretación de vestigios localizados en áreas 
relativamente reducidas, por otra. Es evidente que no existe aún un estudio histórico cultural coherente sobre esta provincia, cuya vasta superficie de más de ocho mil seiscientos kilómetros cuadrados dispone de una amplia gama de diferencias altitudinales y de zonas de vegetación notoriamente contrastadas. Entonces, se trata esta vez de estudiar la historia cultural de los sectores azuayos, aún no reportados arqueológicamente, aproximadamente comprendidos entre $2^{\circ} 30^{\prime} 00^{\prime \prime}$ y $2^{\circ} 53^{\prime} 34^{\prime \prime}$ de latitud sur y entre $79^{\circ} 49^{\prime} 00^{\prime \prime}$ y $79^{\circ} 00^{\prime} 04^{\prime \prime}$ de longitud oeste. Solamente la comprensión de las interrelaciones del hombre con el medio ambiente y consigo mismo permitirá la correcta concepción del desarrollo cultural de la región a investigarse. En el transcurso de la investigación se deben dilucidar algunos problemas conceptuales respondiendo a cuestiones como:

- ¿Confiere o no el sector investigado al concepto "patrón de asentamiento" una definición análoga a la de áreas de geografía semejante, por ejemplo de los Andes septentrionales del Ecuador?

- ¿Podría suponerse que la agricultura intensiva -dado el caso de la existencia de esta actividad en la zona- practicada preferentemente por las sociedades que detentan un patrón de asentamiento nucleado, con sus rasgos propios como la elaboración de insumos que requieren un alto subsidio de energía y elevados índices de planeamiento, sería exclusivo patrimonio de los valles y collados que se benefician o no de la estacionalidad o uniformidad climáticas?

Bien podríamos enunciar una o varias respuestas alternativas; sin embargo, una hipótesis anticipada nos remitiría al riesgo de fundar nuestra opinión en los "viejos" postulados difusionistas o en los de sus doctrinales detractores. Solamente cuando las actividades que realizamos nos brinden los resultados preliminares trataremos de revestir con elementos sociológicos la investigación.

\subsection{Los objetivos}

Es anhelo de los responsables académicos de la P.U.C.E. - S.C. la formación de estudiantes ecuatorianos en arqueología; al finalizar el estudio ellos estarán lo suficientemente capacitados para enfrentar particularmente los diferentes tópicos de la prehistoria andina. Revisemos los objetivos científicos a los que queremos arribar. 
En esencia, nuestro estudio descubrirá las modalidades de ocupación del espacio por parte de las sociedades prehistóricas en cada uno de los períodos y etapas identificables. Período, en este consenso, define la adaptación cronológica de nuestro registro arqueológico a los grandes lapsos nomenclaturales ideados a propósito de las antiguas sociedades ecuatorianas. Etapa, en cambio, es un concepto ambivalente, temporal y estilístico, que caracteriza el comienzo y el fin de una tradición cultural determinada. Las "modalidades de ocupación del espacio" se han concebido como la convergencia del estudio de las formas o modelos históricos de instalación al suelo, de la adaptación tecnológica a los climas y microclimas de la región, de los patrones institucionales de los grupos humanos representados y de la forma más adecuada de apreciar esta convergencia, sin soslayar el establecimiento de la secuencia cronológica, Desde esta perspectiva, los siguientes son los objetivos del presente proyecto:

a. Comprensión histórica de la ocupación del territorio estudiado

a.1. En la historia del clima, sus cambios son conocidos, el hábitat varía. Así, la desértica región del extremo occidental ecuatoriano hace diez milenios detentaba altos índices de pluviosidad comparables a los de la zona ecológica de los manglares, restos de cuyos habitantes han sido localizados en el curso de trabajos arqueológicos emprendidos. Nuestra aspiración es comprender la historia de este cambio gradual -o repentino- y su lateral incidencia en las tradiciones culturales que se disciernan en el Azuay.

a.2. Otro objetivo fundamental es el estudio de los patrones de asentamiento, de la forma de aprovechamiento del espacio por parte de las sociedades identificables. El sector, inmerso en la "zona montañosa de baja latitud" de James, se caracteriza por una alta variabilidad topográfica y climática. La variabilidad se acentúa si consideramos que solamente dentro de un mismo valle las tierras presentan diferencias de composición y calidad con respecto al uso agrícola. Nuestro objetivo es entonces comprender adecuadamente la organización del espacio en esta diversidad topográfica y climática, agrupando bajo los términos de "patrón de asentamiento nucleado" y "patrón de asentamiento dispersado" a los establecimientos que colindan, sustancialmente, en el primer caso, y que no colindan, en el segundo. 
b. El segundo objetivo general tiene que ver con la identificación de la adaptación tecnológica de las sociedades en estudio a los climas y microclimas de la región. Los objetivos específicos derivados de esta cuestión están sujetos a las respuestas que se puedan dar a las preguntas siguientes:

b.1. ¿Representan acaso, los útiles prehistóricos recolectados, adaptaciones singulares a una unidad geográfica menor, es decir, se trata de estilos locales, o, por el contrario, reflejan la expansión de los denominados "horizontes de estilo", que cubren grandes espacios territoriales?

b.2. ¿Existen posibilidades de establecer sincronismos, esto es, de ubicar cronológicamente las tradiciones culturales que se disciernan en lapsos determinados para artefactos de similar factura, forma o decoración que caracterizan zonas prehistóricas aledañas a la región o aún distantes?

b.3. ¿Podemos definir a la región que investigamos como un área cultural, es decir, existen otros elementos que tanto como los estilos morfológicos puedan caracterizar adecuadamente los diferentes momentos, tradiciones o fases que se identifiquen?

c. El tercer objetivo general consistirá en el intento de articulación de los tipos tecnológicos (líticos, cerámicos, metalúrgicos, monumentales) a los patrones institucionales; en otras palabras, nuestra meta es saber cuáles son los usos sociales, las costumbres, asociados verbigracia a las expresiones "Narrio Antiguo" "Chaullabamba", "Cashaloma" o "Tacalzhapa". En este sentido, nos interesa:

c.1. Ubicar los grupos humanos en los diferentes niveles de organización social de Service: Banda, tribu, señoríos, estados antiguos, estados industriales; $y$,

c.2. Caracterizar los sistemas de producción y organización social correspondientes, vida ceremonial, comunicaciones y comercio.

d. El último de nuestros intereses consistirá en resumir los anteriores objetivos en un estudio coherente, que globalice la historia cultural de la provincia del Azuay en los tiempos precoloniales. 
d.l. En efecto, una vez que habremos identificado los diferentes niveles de organización social que existieron en la comarca, tendremos que definir la estática o dinámica culturales que operaron para la aquiescencia de tal o cual nivel tecnológico o para la adaptación a tal o cual sistema de subsistencia. El establecimiento de la historia cultural de la región se realizará mediante análisis comparativos de los materiales superficiales y de excavación localizados en las tres temporadas "sobre el terreno" que estamos ejecutando. Para las fases protohistóricas, esto es, para las tradiciones asociadas al denominado Período de Integración, la utilización de fuentes etnohistóricas tempranas nos ayudará a comprender mejor esta historia cultural. El estudio comparativo del registro arqueológico de nuestra zona será primero un intraanálisis puesto que la región seleccionada, en virtud de su inmensidad, amerita ser indagada sobre las posibilidades de adaptación tecnológica a valles, colinas y espolones que gozan de paralelismos ecológicos.

d.2. El problema filiativo, "affaire" angular de los arqueólogos, será abordado en el contexto de este estudio comparando el material de cada período con sus contemporáneas producciones de áreas culturales adyacentes. En fin, si distinguimos con claridad los usos sociales que nos remitiesen al concepto de Dinámica Cultural, esto es, a elementos evolutivos, trataremos de apreciar el cambio a la luz de los puntos de vista antropológicos modernos. Creemos que si arribaríamos a establecer el carácter de esta evolución y a vislumbrar los parámetros del cambio, en la zona en general o en unidades geográficas seleccionadas, $\mathrm{y}$ a situar convenientemente a nuestros grupos en estudio en el correcto sitial que les corresponda en la evolución social del Ecuador, habremos cubierto con felicidad los otros objetivos generales y específicos.

El alcance de estos objetivos está supeditado a los lineamientos metodológicos que incluye el presente proyecto; en esta virtud, la táctica general comprende las siguientes actividades:

- Estudio de la geografía regional.- El análisis de los factores climáticos y la identificación de microambientes y pisos vegetativos diferenciables, constituirá un buen modelo para entender mejor retrospectivamente, los cambios operados en el paisaje durante los milenios pasados. 
- Prospecciones explorativas y sistemáticas.- Las prospecciones están orientadas a entender la organización del espacio, hacia la determinación de los antiguos patrones de asentamiento. El estudio de los índices de sitios por kilómetro cuadrado y la identificación de las tradiciones más populares, sincrónica y diacrónicamente, nos permitirán elaborar un adecuado mapeo cultural de la prehistoria azuaya. Además, las observaciones de flora y fauna, y el contacto directo con el medio ambiente, nos ayudarán a deducir la simbiosis del hombre con su entorno. En fin, la comprensión de los antiguos modelos de instalación, la localización de elementos arquitectónicos suntuarios, de tumbas, de terrazas de contención, etc. nos permitirán singularizar algunos usos sociales de los grupos azuayos.

- Excavación.- Este importante momento del programa será diseñado para el establecimiento cronológico relativo para las tradiciones culturales que se establezcan. Intentaremos, en el transcurso de sus actividades, obtener muestras de datación absoluta; una adecuada selección de sedimentos para su análisis en laboratorios especializados apoyará nuestro interés por conocer la conformación geológica comarcana y por elaborar un inventario de especies vegetales y animales antiguas. Estos análisis reforzarán además el propósito de conocer los cambios climáticos operados en la zona.

- Trabajos de laboratorio.- Los materiales que constituyen el registro arqueológico del proyecto, sometidos a un riguroso análisis tipológico, a adecuadas comparaciones con estilos circundantes y al establecimiento de secuencias seriadas, nos permitirán comprender los orígenes demográficos y la consistencia cultural de los grupos humanos en los diferentes períodos o etapas.

- Documentación etnohistórica.- A propósito de la etapa imperial, y para el período precedente, el conocimiento de ciertos usos sociales, será apoyado por una selectiva documentación en las fuentes etnohistóricas tempranas. Si nuestro interés reside en describir la historia cultural de la región, la consulta de tales fuentes es insoslayable.

Creemos, esbozando, que las actividades que estamos desarrollando nos permitirán conocer adecuadamente el patrón histórico de asentamiento en la dilatada geografía de la región, la respuesta cultural del hombre al 
medio, el entendimiento del hombre con el hombre como entidad políticosocial, y el carácter general de la evolución social de la provincia; o, lo que es lo mismo, habremos respondido correctamente a las preguntas fundamentales de la prehistoria: ¿dónde?, ¿cuándo?, ¿cómo? y ¿por qué?

\subsection{Las hipótesis}

(Algunas de las ideas se han extraído de las tesis doctorales del investigador responsable; 1982,1984).

Son variadas las teorías concernientes a la explicación del fenómeno prehistórico del área andina. Las similitudes formales de algunos tipos de útiles elaborados en la zona con aquéllos producidos en la altiplanicie mexicana y la selva de Guatemala, por ejemplo, han sido a veces consideradas como el reflejo de un acentuado proceso de interinfluencias. Es muy frecuente encontrar en la debutante literatura arqueológica americana de comienzos de este siglo, una fuerte tendencia difusionista. Y era natural si tomamos como premisa el hecho de que también el pensamiento antropológico europeo orientaba su interés hacia una "salida" del evolucionismo unilineal.

El estudio de la evolución social de las poblaciones andinas nació entonces paralelamente a la búsqueda de un epicentro propagador, a gran distancia incluso, de las conquistas culturales alcanzadas. De esta manera, ni los grandes americanistas como Paúl Rivet y Max Uhle constituyen casos excepcionales. Aparte de las descripciones etnográficas de las poblaciones de la floresta amazónica y de la plataforma andina, Rivet dirigió su interés hacia la explicación de los orígenes del hombre americano; es él el creador de la teoría multidireccional. Al segundo de los sabios mencionados se le debe, en cambio la introducción de la noción de estratigrafía arqueológica para el estudio de la prehistoria de América del Sur. Los métodos modernos de datación absoluta han demostrado que la secuencia cronológica por él propuesta para las antiguas sociedades peruanas sigue siendo esencialmente exacta. Sin embargo, la arqueología contemporánea se ha encargado de demostrar también que gran parte de sus presupuestos conceptuales, a propósito de la cordillera andina del Ecuador, carecen de fundamento. En efecto, está más o menos olvidada en la hora actual la tendencia a aceptar la influencia cultural del área mesoamericana en las antiguas poblaciones ecuatorianas (ver por ejemplo Bouchard, 1982: 8). La base material de los postulados del arqueólogo alemán fue la cerámica recolectada en Narrío, 
provincia de Cañar. Algunos tipos de recipientes, y sus decoraciones, no podían constituir sino claros indicios de un innegable contacto de la población en los tiestos crema-pulidos representada, con aquella asentada en la zona maya. Sus aseveraciones lograron arraigarse de forma tal que hasta mediados de este siglo, los más importantes prehistoriadores suponían que las prácticas de sedentarización y sus rasgos concomitantes deberían explicarse estudiando las similitudes de la cerámica producida en las dos zonas. La influencia del autor germano en Jacinto Jijón y Caamaño es evidente (1952); solamente que Jijón busca el epicentro en dirección opuesta, en la elevada puna peruano-boliviana, hábitat de la cultura Tiahuanaco. Por otra parte, el estudio de los rasgos cerámicos de la más antigua fase establecida para la cultura "Valdivia", extremó la posición. En esta virtud, las investigaciones de Emilio Estrada, Clifford Evans y Betty Meggers indujeron a suponer que la incipiente agricultura de la península de Santa Elena, y por ende del continente, debería ser una derivación de aquella contemporáneamente practicada a un nivel similarmente hortícola en "Jomón", Japón, en razón de la extraordinaria semejanza en las formas y modelos de diseño cerámicos. Los postulados de las últimas tendencias antropológicas, funcionalistas y estructuralistas, han servido para apreciar el fenómeno desde una perspectiva diferente. Ambas tendencias preconizan la comparación del conjunto de rasgos culturales, cada uno de los cuales es absolutamente indispensable en el funcionamiento de la "estructura" social. La más grave imputación a los difusionistas es por haber pretendido que algunos productos aislados de la cultura material, particularmente la cerámica, serían suficiente base para la explicación del problema de los orígenes.

A pesar del cambio de visión del fenómeno cultural andino, había que buscar una solución valedera al problema de filiación, el de los contactos culturales. Efectivamente, no se puede negar, desde épocas tan tempranas como Narrío Antiguo o Valdivia, ni la existencia de relaciones de intercambio entre la alta plataforma andina y las llanuras del litoral ecuatoriano, por ejemplo, ni la vigorización del trueque en las épocas posteriores.

A partir de los años cincuenta, el pensamiento etnológico para la región andina ha estado fuertemente vinculado al estudio de la organización del espacio y está basado en las divergencias existentes, también durante la mitad primera de la presente centuria, entre dos puntos de vista diferentes para examinar geográficamente los Andes Centrales Tropicales (de Puna). 
El determinismo geográfico de Isaiah Bowman produce una antinómica doctrina indigenista iniciada por Cari Troll (Dollfus, 1978: 7-21). Bowman estuvo preocupado por encontrar esquemas de desarrollo para las sociedades andino-tropicales, siempre dentro de un esquema "mercantilista". Para él, las sociedades andinas ubicadas sobre los tres mil metros de altura estaban fatalmente desfavorecidas a causa del rigor climático, del consumo de la coca y el alcohol, y el progreso peruano debería venir de la floresta amazónica y de los abrigados valles costaneros, es decir, de los lugares en donde se podían cultivar los productos de exportación, particularmente el caucho. Muy diferente es el análisis de Troll. El se preocupa, sobre todo, de entender el problema de la organización de espacio desde una dimensión más bien histórica. Según este autor alemán, básicamente, es el aprovechamiento de diferentes pisos ecológicos por parte de una misma población la característica fundamental de las sociedades andinas durante toda su historia. Desde esta perspectiva, el estudio del potencial económico y de los factores climáticos reinantes en cada piso ecológico es importante; pero es importante también la organización espacial de las sociedades andinas, el dominio del medio natural por el hombre; solamente la clara comprensión de la interrelación del hombre con el medio y consigo, puede explicar científicamente el problema del desarrollo histórico de las sociedades andinas y el de los orígenes. El estudio del medio natural, del aprovechamiento de los recursos generados en cada "piso" ecológico y el de las más antiguas fuentes etnohistóricas, permitieron a Murra (1975) deducir que es el control vertical de los recursos la explicación más conveniente del desarrollo de las sociedades tardías (Intermediario Reciente: 800 - 1500 d.C. en Perú; 500 - Siglo XV d.C. en Ecuador).

Dentro de este marco de conceptos, con el afán de incorporar a los suyos propios, de concepción de las modalidades de ocupación (les structures de l'habitat), este problema ha motivado la elaboración, por parte de Danièle Lavallée y a su equipo del CNRS (URA 25), con las diferencias metodológicas correspondientes, de varios programas de investigación arqueológica en algunos países andinos (Lavallée 1977, Lavallèe y Julien 1983, Bouchard 1983, Guffroy 1983).

Los innumerables ramales y espolones, valles y hondonadas, ríos y riachuelos de temporada y permanentes, en fin, la variación climática que comporta la dilatada geografía del Azuay, son aspectos naturales ambivalentes con la historia social, por eso el programa ha incluido actividades de prospección. El análisis de los problemas que tratamos de 
resolver estará centrado en la consecución de los objetivos señalados y depende del potencial arqueológico de la provincia, es decir, de la naturaleza de los asentamientos, de la época, y del interés conceptual que puedan suscitar estos restos. Sin embargo, consideramos que el vislumbre del engranaje institucional y de los patrones consecuentes en cada período es meta de la investigación; es interesante entonces formularse algunas interrogantes o enunciar las afirmaciones en torno a los problemas que trataremos más adelante, en el futuro.

- ¿Tuvo la práctica de la caza de animales serranos y costeños, que se observa hasta la actualidad, un precedente tal vez precerámico aparte del yacimiento paleolítico de Chobschi, al oriente de la zona?

- Y si, en efecto así habría sucedido, ¿Comparten estos antiguos grupos cazadores el sentido de "verticalidad" discernido para las bandas paleolíticas del Septentrión andino del Ecuador (Salazar 1980)?

- El área que se investiga es una zona geográfica cuyos valles bien pudieron constituir brechas naturales que tornaron fácil el movimiento poblacional; es de esperarse entonces la localización de sitios formativos evidenciados quizá por la confluencia de Narrío Antiguo y Catamayo I, fases más o menos coetáneas; en este sentido, ¿Corresponde la población representada en los sitios del período Formativo a una oleada exógena de dirección variada, o representa más bien la continuación de un proceso ya generado?

- La discusión del mismo problema y su incidencia en los períodos posteriores nos hará considerar primero que el material arqueológico recolectado nos permitirá singularizar las esferas morfológicas y filiativas de la zona, de las que se deducirán algunas pautas definidas de cultura. Sin embargo, los restos que se descubren (cerámicos, líticos, arquitectónicos), por su naturaleza, no agotarán las posibilidades explicativas de temas tan interesantes como la organización económica o la estructura social. Habrá, en segundo lugar, que particularizar acentuadamente la importancia que reviste el estudio del hábitat y sus correlaciones con los rasgos establecidos, $\mathrm{y}$, alternativamente, el de la transformación del paisaje por el hombre. 
- El sector a investigarse está inmerso en la región Sur de los Andes Septentrionales. La cordillera andina no es uninominal pues hay que distinguir los Andes de "páramo" en el Ecuador y en el Norte peruano, de los de "puna", que se extienden al Sur de una línea que pasaría por Trujillo (Salomón 1981?: 52-61). Consignamos esta dicotomía porque consideramos que deberíamos partir de una sospecha insoslayable. ¿Deberían reflejar, las tardías sociedades a investigarse, similitudes estructurales con los diferentes grupos humanos sucesiva o alternativamente asentados en las otras regiones de "páramo", cuyas características no parecen haber hecho necesarios ciertos logros culturales resumidos en un control económico imperial o en la instauración de prácticas pastoralistas, como en la "puna"?

- Por último, las tardías sociedades de la zona serán enfrentadas dentro del problema general de la evolución social. La vecina área de Cañar presenta aparentemente en su registro arqueológico una dicotomía filiativa para el período de Integración. Una de las dos fases tardías, "Cashaloma", es la continuación estilística de una antigua tradición alfarera (Narrío Temprano), cuyas formas y diseños continúan en el período de Desarrollo Regional (Narrío Moderno), influye en los patrones cerámicos de los conquistadores incas y reflorece en los albores de la etapa colonial (Jaramillo 1976). El otro grupo humano, "Tacalzhapa", en cambio, es una posible derivación de culturas establecidas en la provincia de Chimborazo, en la sierra central ecuatoriana, y en la Amazonia; en este sentido, el material tardío del que nos ocupamos, ¿refleja la culminación de un proceso evolutivo generado en épocas anteriores, o, por el contrario, ha sido elaborado por una población instalada durante el último lapso transcurrido entre los períodos de Desarrollo Regional e Inca?

\subsection{Variables metodológicas}

\subsubsection{Trabajos de campo.}

2.4.1.a. Prospecciones.- Tienen como finalidad el estudio de la distribución espacial de los asentamientos. De acuerdo a nuestro cronograma de actividades, la etapa inicial que estamos cumpliendo, tendiente a una inicial evaluación cuantitativa y cualitativa del potencial arqueológico de la 
provincia, está consagrada a la recolección de informaciones sobre áreas no estudiadas y a la verificación de las mismas mediante informaciones no sistemáticas, esto es, que no corresponden a un previo proceso de reticulación del terreno. Concomitantemente a estas exploraciones se ha realizado parcialmente el estudio del material prehistórico proveniente del Azuay que figura en las colecciones particulares de Cuenca.

El registro de los sitios durante estos recorridos no sistemáticos, y de los que se descubran durante los recorridos sistemáticos, se lo realiza en una hoja de prospección. Las variables que incluye este formulario son las siguientes:

- Número de sitio, por orden de localización.- En determinadas circunstancias, cuando una loma dispone de espolones ocupados sin evidente continuidad entre unos y otros, al mismo número lo asignamos literales para una mejor singularización.

- Nombre del sitio.- La experiencia anterior en este tipo de trabajos nos remite a la consideración de que los nombres de los sitios deben estar acordes con la relación toponímica correspondiente. Así, serán los nombres de los ríos permanentes o itinerantes, las cordilleras locales, lomas, colinas, espolones, crestas y cuchillas, los que figuran en este acápite en las hojas de prospección. De igual manera que para el número de sitio, cuando espolones independientes constituyen sitios diferenciables, y la relación topográfica para la nominación es única, el nombre de cada sitio va acompañado de un numeral que les caracteriza; por ejemplo, Guaylo 1, Guaylo 2.

- Longitud, latitud, altitud.- Estas tres variables se calculan en las hojas topográficas luego del mapeo correspondiente.

- Ubicación topográfica.- Este acápite es muy importante para el logro de los objetivos postulados. Se trata de una completa descripción de la realidad topográfica que constituye el sitio arqueológico y de su particularización frente al entorno inmediato. Quien prospecta un sitio, para describir adecuadamente su ubicación topográfica, debe, mediante "pruebas de lampa", es decir, pequeños sondajes de medio metro cuadrado, reconocer toda la ocupación cultural visible, las dimensiones del asentamiento. El cálculo del área de ocupación nos ayudará a distinguir con claridad el uso del 
suelo en cada época. Hay que anotar que la singularización del yacimiento frente a su entorno inmediato incluye la descripción total de barrancos, escarpes, remociones naturales y artificiales, presencia de elementos modernos, etc.; se recomienda tomar como referencias a obras de infraestructura (caminos, puentes, iglesias, escuelas) cercanas al yacimiento. Nuestro interés es que los datos que contienen la ubicación topográfica permitan a otros investigadores acceder con seguridad al sitio.

- Geología, vegetación y fauna.- La conformación general del terreno, el color y textura de las capas, son descritos en cada sitio. A pesar de que el estudio geográfico comportará una introducción geológica regional, la individual descripción de la antigua remoción de estas capas podría tener como fin la demostración de que la erosión tiene un alto significado cultural. Se anotan exhaustivamente todas las especies vernaculares y foráneas de flora y fauna del sitio.

- Naturaleza y descripción.- Acápite muy importante que reporta el tipo de elementos que contienen el sitio: Arquitectónicos, inhumacionales, cerámicos, líticos, metalúrgicos, óseos, etc. Particularmente importante es la descripción de concentraciones de material, las que indican eventualmente el sector de sondaje preliminar o preparar la excavación. Es recomendable sondear en un metro cuadrado, utilizando niveles arbitrarios de 15 ó $20 \mathrm{~cm}$. de profundidad, para reportar los cambios sedimentológicos, la presencia o ausencia de pisos ocupacionales y la profundidad de la capa cultural. Estos sondajes no se realizarán si las remociones de los huaqueros o las labores agrícolas o de otra naturaleza (trincheras militares por ejemplo) evidencian ya estas informaciones. Es recomendable anotar minuciosamente todas estas remociones, la profundidad hasta la que han sido afectados los sectores arados, el tipo de arado (tracción animal o mecánica), la profundidad alcanzada por las raíces de los árboles y otros vegetales, los índices de erosión, la presencia de áreas.de combustión, canteras, pavimentos, etc.

- Materiales recolectados.- Los materiales a los que se refiere el acápite son aquellos que serán estudiados en el laboratorio. Se pueden ya realizar los primeros agrupamientos de acuerdo a su naturaleza cerámico, lítico, conchífero, óseo, carbónico, metalúrgico, tejidos, cestería, restos de flora, cropolitos, etc., que 
está conservado en sendas fundas, o bien se pueden guardar en el campo indistintamente todos los materiales recolectados en un sitio, en una sola funda, para dividirlos en el laboratorio cuando se elabora el catálogo de "materiales de superficie". Cada funda será identificada por una tarjeta impresa en la que consta el cantón, la parroquia, nombre y número de sitio, el nivel, el nombre de quien recolectó los materiales y el contenido. Posteriormente se agregará el número que le corresponde en el catálogo.

- Número de fotografía.- Es recomendable tomar una o dos fotografías de cada sitio y elaborar un catálogo que nos permita manejar adecuadamente esta documentación; A veces la fotografía brinda información complementaria sobre la ubicación topográfica del yacimiento.

- Fechaje.- Únicamente cuando existe la absoluta seguridad del período al que pertenecen los materiales será atribuido un fechaje relativo para los mismos. Caso contrario, será un signo de interrogación (¿?) el que provisionalmente figure en este acápite.

En fin, si las informaciones de la ficha de prospección rebasan el espacio de la misma, se utiliza una hoja suplementaria o de continuación general.

El estudio del material superficial y de los sondajes practicados en los sitios descubiertos en esta primera etapa, nos permitirá atribuir este material a los grandes períodos de ocupación de la zona y programar un selectivo programa de trabajos, lo que nos obligará a aprovechar tanto las diferencias altitudinales cuanto las inherentes dificultades del paisaje.' La reticulación de cuatro o cinco zonas de recorridos sistemáticos nos permitirá circunscribir arqueológicamente el área que nos interesa y la caracterización cultural correspondiente. La estrategia a utilizarse durante este trabajo estará condicionada a la conformación y distribución de los espolones, crestas, lomas, hondonadas y valles reticulados, a las dificultades o facilidades de acceso y al tipo de vegetación que se confronte.

La repartición geográfica de los sitios se la realizará en mapas de cada una de estas zonas, elaborados, a partir de las cartas topográficas 1:25.000 preparadas por el Instituto Geográfico Militar, mapas que serán simplificados por el dibujante del proyecto. Si durante las exploraciones 
iniciales son dos las personas que, prospectan la zona, las áreas reticuladas (de treinta a cuarenta kilómetros cuadrados) para la prospección sistemática requerirán el concurso de seis personas; y, si las dificultades presentadas por la vegetación; sobre todo en las regiones tropicales, son notorias, contrataremos los servicios de dos o tres macheteros.

Diariamente pensamos cubrir bandas, de terreno de un kilómetro de ancho por cinco o seis de largo. Se trabaja en jornada única de siete horas, durante las cuales cada persona es responsable del registro, mapeo, sondajes y recolección de materiales de por lo menos un sitio arqueológico. El presupuesto del proyecto incluye la adquisición de carpas por lo que el campamento lo instalaremos en un sector estratégico de cada zona reticulada. Repetimos, las zonas de prospección sistemática deberán presentar una marcada variabilidad altitudinal, condición. sine qua non para alcanzar los objetivos postulados.

2.4.1.b. Excavación.- Los sondajes practicados en las etapas prospectivas nos permitirán balancear el valor cultural de cada sitio, el contenido y sus condiciones de preservación. Los yacimientos que comporten niveles de ocupación no perturbados ("suelos" arqueológicos) serán evaluados en su importancia' y se escogerá, por el momento, uno solo para la excavación. El criterio predominante para la selección del asentamiento a excavarse, de entre todos aquellos que presenten suelos de ocupación in situ, tiene que ver con los objetivos que se persiguen, pues deberá presentar, en lo posible, muestras que manifiesten claramente la variabilidad cultural que denominaremos fases o etapas y una evidente superposición temporal. La cuadriculación del terreno la realizaremos con teodolito; se diseñarán secciones, unidades y subunidades o cuadrículas; estas últimas tendrán un metro cuadrado de superficie, nominadas con letras de norte a sur y con números en sus coordenadas este-oeste. Para la cuadriculación se utilizarán clavos metálicos de cuatro pulgadas y cuerda elástica. Así mismo, está prevista la construcción de andamiajes de madera de treinta y cuarenta centímetros de altura para evitar el contacto de los excavadores con los suelos arqueológicos. La altura de cada elemento será determinada en relación a un punto cero, escogido al inicio de la excavación, y será igualmente calculado con la ayuda del teodolito, instrumento que nos servirá además para el levantamiento topográfico del yacimiento y para calcular los perfiles estratigráficos de las secciones verticales de la excavación. 
La excavación consistirá en el desbastamiento horizontal de capas de ocupación, es decir, se utilizará lo que eh arqueología se denomina estratigrafía natural. De esta manera el levantamiento de las muestras no se ejecutará sino después de que todo el "piso" arqueológico haya sido puesto en evidencia y de que se hayan levantado planos y tomado fotografías verticales de cada subunidad o cuadrícula. Esta última actividad nos permitirá en el futuro, elaborar un mosaico fotográfico vertical de todo el pisó. El levantamiento de los elementos sé realizará luego de la numerotación de cada uno; éstos se conservarán en fundas para el análisis de laboratorio posterior. Este procedimiento será utilizado para todas las capas de ocupación humana, las que temblarán a la profundidad en la que comience la capa arqueológicamente estéril. El cernimiento de la tierra extraída de los diferentes estratos de la excavación, nos permitirá obtener muestras de microfauna y microvegetación antiguas, preciosas para alcanzar nuestros objetivos; estas muestras, conjuntamente con las sedimentológicas de cada nivel, serán examinadas en laboratorios especializados.

\subsubsection{Trabajos de laboratorio.}

Los análisis de materiales serán realizados en un laboratorio instalado en el complejo arquitectónico de la P.U.C.E.-S.C., el mismo que dispone de estantería adecuada y de los materiales que lo conforman. Este laboratorio comprende además otro, de fotografía, y un suplementario, de restauración.

El análisis de laboratorio comprende el lavado, catalogación y la clasificación propiamente dicha. El lavado se lo realiza, en lo posible, el mismo día de la localización de las muestras.

Habrán dos catálogos: uno para los materiales de prospección, que comenzando con el 00001, consignará la división del contenido cultural de cada sitio por materiales. Así por ejemplo, el material cultural de un sitio, consistente en fragmentos de cerámica, huesos y esquirlas líticas, figurará en el catálogo con tres diferentes números: 0001, cerámica; 0001, lítica; y, 0003, hueso. Cada funda de esta manera, tendrá un número en el catálogo de acuerdo al material que contiene; esto ayudará eficazmente a la ordenada manipulación de los materiales en el laboratorio. Este catálogo contemplará el nombre y número de sitio, cantón, parroquia y nivel. Se podrá prever también dos casilleros adicionales que nos indiquen si el material está ya 
inscrito o estudiado. Con ligeras variantes se elaborará un catálogo para el material de la excavación en el que se diseñarán casilleros en el que, indistintamente, figuren la profundidad correspondiente, la sección, la unidad y la subunidad. Para agilitar la elaboración de este catálogo, procuraremos realizarlo en el momento mismo del levantamiento de las muestras.

La inscripción de los fragmentos se lleva a cabo sobre una película de esmalte, con tinta china y a pluma; se exige legibilidad en la escritura y, de acuerdo a las normas internacionales, la inscripción de los materiales de superficie comienza siempre con la legra O, que corresponde a "Ecuador", seguida por la letra A de "Azuay", las iniciales del nombre del sitio, su número y su nivel. La inscripción de los fragmentos localizados en la excavación podrá excluir el número de sitio, pero agregar la sección, la unidad y la cuadrícula. Podría rematar la inscripción en ambos casos, con la inclusión de los dos últimos dígitos del año correspondiente.

La clasificación de los materiales, tanto de superficie como de excavación, tendrá tres momentos esenciales: Establecimiento tipológico, ordenamiento cronológico y comparación.

- El establecimiento de los "tipos" de material cultural prehistórico se lo realizará en base a la selección de criterios clásicos, de a- cuerdo a la naturaleza de las muestras. Básicamente, serán los materiales cerámicos y la producción lítica (del período precerámico o asociada a la utilería cerámica posterior), los que ameriten la abstracción de tipos por parte de los investigadores. Los "atributos" que serán utilizados para la discriminación y particularización de los tipos, serán obtenidos de los conceptos de morfología, técnicas de elaboración y función.

Los materiales líticos serán agrupados en diferentes categorías morfológicas y funcionales $\mathrm{y}$, aunque se tratase de minúsculas esquirlas localizadas en las prospecciones o elementos "fugaces", extraídos de la excavación, serán estudiados para determinar los planos, bulbos y ondas de percusión, los eventuales retoques y la posible asociación a actividades desarrolladas en campamentos semipermanentes, abrigos rocosos, etc. El agrupamiento en categorías morfológicas (bifaces, raspadores, raederas, propulsores, buriles, escoriadores, hachas, obras de arte, etc.), orientará igualmente su interés hacia la comprensión de los usos culturales en general, 
$\mathrm{y}$, en particular, hacia la identificación de los sistemas de subsistencia de estos antiguos grupos surecuatorianos. De acuerdo a su distribución en la superficie de la excavación o en los diferentes niveles de la misma, los tipos que se obtengan pueden ser estudiados estadísticamente, lo que desembocará en la elaboración de curvas cumulativas, y aún, se puede intentar una explotación informática de los datos tipológicos. Tanto para el material lítico, como para el cerámico, el dibujo concebido bajo normas internacionales acompañará a la descripción tipológica.

El agrupamiento de los fragmentos cerámicos se realizará también en base a una adecuada selección de sus "atributos". Así, el estudio de la pasta de los tiestos se establecerá tomando como criterios diferenciabas a las siguientes categorías: -Índice de cocción, desgrasantes o elementos atemperantes, atmósfera de cocción, espesor, dureza y tratamiento de superficie. La técnica de elaboración será detalladamente descrita.

Los elementos de descripción morfológica serán agrupados en bordes, asas, fondos y sección corporal. Con anterioridad a la abstracción tipológica general, el estudio ceramológico consistirá en una detallada descripción de estos elementos utilizando siempre una nomenclatura adecuada; así, los bordes deberán ser analizados de acuerdo a su dirección u orientación (oblicuo-externa, oblicuo-interna o vertical), a su forma (cóncava, convexa o rectilínea), a su terminación o labio (redondo, planimétrico, afilado, a bisel), a su decoración y a su diámetro. En las asas, particularmente importante es la técnica de manufactura y su fijación. El diámetro de los fondos y la técnica de elaboración, son elementos que describirán a estos agrupamientos, sin olvidar que la descripción de su silueta podría favorecer una mejor distinción de la variedad de usos culturales. Así mismo, el reconocimiento de los puntos de tangencia vertical externos e internos, de los sectores de inflexión o intersección, y de la forma, abierta o cerrada, de los fragmentos corporales, será minuciosamente descrito. Pensamos que la estrategia concebida podrá ser enriquecida a medida que avancen los análisis de laboratorio. Se establecerán luego los tipos cerámicos genérales utilizando atributos de forma y de decoración e incluyendo por asociación los otros criterios, es decir, la pasta y la técnica de manufactura. Trataremos de evitar el doblamiento o triplicamiento de la nomenclatura de los tipos ya establecidos en pequeños sectores de la provincia. Nuestro propósito será, contrariamente, el tratar de unificar la desconcertante nominación pluralizada de los vestigios que deberían ser reconocidos bajo un solo nombre. Las categorías cerámicas establecidas 
sobre el registro arqueológico superficial, que incluirán abstracciones del material de sondajes preliminares y de sectores de alta erosión, nos remitirán a la comprensión del reparto tipológico en el espacio y, eventualmente, de la secuencia cronológica de los tipos regionales.

- Sin embargo, un refuerzo importante para el establecimiento de la secuencia cronológica de los tipos cerámicos azuayos constituirá el análisis porcentual de la frecuencia de popularidad en los diferentes estratos de la excavación, es decir, en el tiempo. El análisis estadístico permitirá la elaboración gráfica de secuencias seriadas que explicarán claramente la evolución de la alfarería regional. Posteriormente serán ratificados o rectificados los fechajes relativos que se proponga, con el apoyo de las fechas que se obtengan con métodos de datación absoluta.

- Por último, el análisis tipológico será sometido luego a una exhaustiva comparación con las muestras culturales circundantes para arribar a una adecuada comprensión del flujo cultural andino en sus diferentes momentos y para determinar, quizás, el origen u orígenes de las tradiciones culturales que estamos descubriendo.

\subsection{Trabajos relacionados con el tema, realizados en el exterior}

La investigación arqueológica implica una primera etapa condicionante de las subsiguientes, etapa que se realiza en la realidad geográfica en donde estuvieron inmersos los grupos humanos cuya evolución cultural se indaga. Esta consideración ha hecho que en algunas ocasiones, el registro arqueológico recolectado en el Ecuador, o una parte del mismo, haya sido procesado en las instituciones o universidades de donde provinieron los investigadores correspondientes. Desde este punto de vista, podríamos incluir en este rubro todas las investigaciones realizadas por científicos extranjeros. Sin embargo, tenemos que admitir que la provincia del Azuay ha sido arqueológicamente muy poco conocida. Los prehistoriadores norteamericanos D. Collier y J. Murra se ocupan marginalmente de ella pues, la abundancia de material cañarense y el conflicto armado con el Perú, no permitieron el estudio del resto del austro andino del Ecuador, como estuvo previsto. Durante los mismos años cuarenta, el valle de Chaullabamba fue estudiado por W. Bennett, como lo fue un poco antes por M. Uhle, y posteriormente por Estrada, B. Meggers y C. Evans, quienes han establecido las mencionadas pautas introductorias a los estudios regionales en 
arqueología. El espíritu conceptual de nuestro proyecto se consolidó a partir de los años setenta, época en la que, con los aportes de Murra, se postula el estudio total de la interacción hombre-medio ambiente y hombre-hombre, como estrategia insoslayable para el análisis de la producción cultural andina. En los mismos años setenta, una sección del valle del río Jubones fue motivo de interés arqueológico por parte de la Universidad de Londres, cuya delegación estudió un pequeño sector del suroccidente azuayo. Pensamos que el contexto del presente programa de investigaciones arqueológicas en el Azuay podría contribuir, además, a sistematizar y unificar, los sistemas nomenclaturales propuestos por los diferentes estudiosos para la comarca.

\subsection{Trabajos relacionados con el tema, realizados en el país}

Nos referiremos en este rubro a algunas experiencias del investigador responsable en diferentes trabajos arqueológicos emprendidos en el Azuay y áreas circundantes.

- Participación en la segunda temporada de excavaciones en el conjunto pre y; protohistórico de "Todos Santos" de Cuenca, dirigido por Mario Jaramillo Paredes (Jaramillo, Almeida, Martínez y Landívar 1975). Se intentó estudiar la reutilización del material incaico en la arquitectura de la "antigua" ciudad, fundada por los españoles en 1557.

- Bajo la dirección y asesoramiento de José Alcina Franch, participación en las investigaciones en el monumento incásico de Ingapirca, Cañar, entre 1975 y 1978 (Almeida 1978). El análisis de la gran producción cerámica de los pueblos instalados en el sector antes de la incursión austral permitió deducir, tanto como lo había previsto M. Jaramillo (1976), que las tradiciones culturales que preceden a la corta sumisión política a los conquistadores cuzqueños habían sido arqueológicamente subestimadas. La gran mayoría de investigadores, continuando el cometido iniciado por M. Uhle, había concentrado su interés casi exclusivamente en los descubrimientos espectaculares, notoriamente en los restos de arquitectura inca.

- Durante el verano de 1978, codirección de una campaña de excavaciones organizada en la cordillera Occidental de los Andes, en un medio natural semejante al de Ingapirca (3200 - 3300 m. de 
altura), en Pucará, provincia del Azuay (Almeida y Montes del Castillo 1981). En esta ocasión el interés estuvo centrado en el estudio de la cerámica y demás restos de un área de 100 kilómetros cuadrados. Este trabajo sirvió para reforzar las posibilidades de demostración de la existencia del trueque durante el período Formativo, entre la sierra Sur y algunas poblaciones de la costa Central, y permitió redactar un informe que reportaba la presencia de similares tipos cerámicos establecidos por Collier y Murra en el Noreste cañarense durante los años cuarenta.

- Experiencias de reconocimiento sistemático adscritas al proyecto "Tahuín", en el extremo meridional de la costa del Ecuador, en el valle del río Arenillas, provincia de El Oro. El interés estuvo centrado en el salvamento de una zona que debía ser alterada por las aguas de una presa y fue dirigido y ejecutado por Jorge Marcos, Olaf Holm y Patricia Netherly en 1978 y 1979. El medio natural era diferente; el matorral espinoso seco de 1,50 m. de altura y zonas de manglares fueron prospectados minuciosamente, tratando de responder siempre a las interrogantes que presenta el problema de la adaptación tecnológica a una agricultura itinerante de quema y roza y a pisos ecológicos tropicales diferentes.

- Hasta 1979 el extremo Sur de los Andes ecuatorianos, esto es, el de la meridional provincia de Loja, era desde el punto de vista arqueológico, absolutamente desconocido. Los objetivos generales de la misión franco-ecuatoriana que inició sus trabajos en 1979 estuvieron encaminados al establecimiento de la secuencia cronológica de un área geográfica de cerca de 4000 kilómetros cuadrados, y a la singularización de los modelos de subsistencia para cada período a determinarse, dentro del amplio contexto, de los patrones antiguos de asentamiento. Bajo la dirección de Danièle Lavallèe, responsable de la unidad 25 del Centro Nacional de Investigaciones Científicas de Francia (CNRS), doscientos treinta y dos sitios arqueológicos fueron descubiertos por los miembros del proyecto en el cual el autor de este informe colaboró como contraparte técnica del Ecuador entre el año mencionado y 1982. Únicamente el valle bajo del río Catamayo, a los alrededores del cantón homónimo, presentó evidencias de ocupación formativa. Las tradiciones culturales que Guffroy (1981) denomina Catamayo I, II y III, corresponden a sucesiones estilísticas en la producción alfarera 
$\mathrm{y}$, por tanto, a una superposición evolutiva, en el tiempo, de los primeros grupos aborígenes arribados a la zona. La agricultura "de falda de montaña", discernida para el período subsiguiente, el de Desarrollo Regional, representado en el mismo valle, pero también en los espolones aledaños a los ríos de temporada Playas y Trigopamba, de Catacocha y Cariamanga, respectivamente, y que el mismo Guffroy (1981) denomina Catamayo IV y V, Catacocha I y II y Cariamanga I y II. La más extendida fase alfarera del Sur de esta provincia es la "Zarza", que corresponde a la ocupación humana durante el período de Integración, de los sectores mencionados y de Vilcabamba. La instalación de cumbre con un patrón de asentamiento nucleado, en la acepción de sectores de la población con unidades domésticas básicas colindantes combinados con aquellos en donde las unidades domésticas básicas no colindan entre sí, fue verificada por lo menos en un centenar de sitios. La dilatada geografía de la comarca permitió realizar un trabajo selectivo, que terminaría en la elaboración, de nuestra parte, de dos tesis doctorales. Extrañamente, en el extremo Sur del área investigada, en Macará, no fue posible verificar la presencia de claros indicadores estilísticos de la cerámica "zarza". Sin embargo, si estas decoraciones no han sido descubiertas, tenemos que admitir que el mismo grupo está representado en todo el Sur de la provincia por enormes urnas cerámicas de fines funerarios. El flujo cultural con los poblados de la costa peruana parece corresponder a tardíos desplazamientos imperiales (mitimaes) o a un vigoroso intercambio comercial. Debemos mencionar además que se localizaron numerosos restos incaicos en diferentes sectores del Sur de la provincia de Loja.

\section{LOS TRABAJOS EMPRENDIDOS}

\subsection{Sobre el terreno}

Inicialmente no habíamos previsto reportar resultado alguno puesto que el informe final, que se redactará en el futuro, deberá comportar la verificación o modificación de las hipótesis formuladas. Los cinco meses transcurridos desde el comienzo de los trabajos no nos han permitido sino apreciar panorámicamente las articulaciones de los hombres prehistóricos 
azuayos con los medioambientes existentes y vislumbrar, menos claramente, la historia cultural y su secuencia.

De acuerdo a lo programado, hemos explorado algunas lomas existentes en la zona irregularmente trapezoidal cuyo vértice noroccidental se ubica en el valle bajo del Río Chico, en Zhumiral, perteneciente a la parroquia Ponce Enríquez, ecológicamente correspondiente a lo que los fitólogos denominan "matorral espinoso seco", floresta típica de la planicie del litoral ecuatoriano. Dicho valle, situado a ocho metros de altura sobre el nivel del mar, está encerrado por el septentrión y por el meridión, por depresiones y crestas selváticas de hasta $250 \mathrm{~m}$. de altura. El límite nororiental de este trapecio está constituido por los elevados macizos de la cordillera oriental de los Andes, que de forma particularmente escarpada encierran el estrecho valle del río Paute, en las inmediaciones de la parroquia Palmas, del cantón Paute. La altitud media del sector (2900) favorece la formación de extensos pastizales aunque los paisanos de Palmas, cerca de la margen izquierda del caudaloso Paute, siembran actualmente diferentes productos tropicales y cosechan entre otras cosas tres veces al año, maíz de diferentes subespecies. En Zhumiral, la ocupación humana antigua fue descubierta en las vegas del río Chico; aquí en Palmas, se concretó más bien a partir de la segunda hilera de colinas, que dispone de varios arroyuelos y que acredita un importante índice de precipitaciones. El vértice suroriental del trapecio imaginario tiene una altura media de 2700 m.s.n.m., y topográficamente corresponde a un conjunto montañoso de gran escarpe, alta erosión, y a valles y hondonadas irrigados por diversos riachuelos discurrentes hacia el Levante y confluentes de la arteria fluvial más importante del sector, la quebrada Tamboshuaycu. En uno de estos pequeños valles se ha construido el centro parroquial de Nabón, villorrio fundado por los españoles durante la etapa colonial. En el sector no llueve mucho y la vegetación, arbustiva y cactácea, no es demasiado densa. La intensiva ocupación del hábitat se ha verificado durante los recorridos realizados sobre algunas cumbres, sectores priorizados por el grupo humano representado, para uso residencial. El vértice suroccidental del trapecio mencionado está constituido por los sectores boscosos existentes a partir de la margen izquierda del río Jubones en su curso inferior. La margen derecha del río pertenece a la provincia de El Oro y el único poblado azuayo de nuestra zona es Chilcaplaya, recinto perteneciente a la parroquia Shalug (San Rafael), del Cantón Santa Isabel. La altura promedio del sector es de 500 m.s.n.m., y desde el punto de vista climático, tanto como Zhumiral y la costa ecuatoriana en general, no dispone sino de inviernos y veranos. Existen colinas en las 
que se ha aplicado un desbroce forestal intenso lo que nos ha permitido vislumbrar un patrón de asentamiento dispersado pues no existe continuidad de insumos culturales de los asentamientos habitacionales seguramente comprobables en las cimas de los pequeños promontorios. Hemos explorado además algunas zonas ubicadas dentro del área delimitada por los cuatro sectores mencionados y, aguas arriba del Machángara, hemos descubierto un sitio (Saucay), ubicado 10 kilómetros al norte de la línea que uniría Zhumiral con Palmas. En el futuro pensamos recorrer la zona de Molleturo, en la cordillera occidental, para completar las zonas delimitantes dé manera que será un área pentagonal la que acredite nuestro interés. Hemos visitado sectores cercanos a la capital de la provincia, verbigracia los espolones de la margen izquierda del río Patamarca, cerca de Sinincay, parroquia situada a 8 $\mathrm{km}$. al noroeste de Cuenca. Al oriente de Sinincay, en Checa, Chiquintad y Llacao, hemos podido verificar una importante ocupación humana preimperial que aprovecha generalmente las cumbres de las lomas como patrón preferencial de asentamiento. El sector centro oriental de Gualaceo ha sido también objeto de nuestros recorridos; en efecto, abundantes restos culturales que incluyen estructuras de arquitectura han sido registrados en las lomas que dominan la quebrada Chusquín, cerca de la desembocadura en el río Santa Bárbara, en los alrededores de la parroquia San Juan. La variada tradición artesanal que se observa en Chusquín está también presente en las cimas de los promontorios adyacentes a la confluencia de los ríos Santa Bárbara y San Francisco. Complementariamente, hemos registrado algunos sitios en Girón, San Fernando, Guachapala y Sígsig. Hasta el momento hemos descubierto 39 sitios arqueológicos.

\subsection{En el laboratorio}

El trabajo de campo orientó su interés también hacia el descubrimiento de abrigos rocosos, grutas, grabados, pinturas rupestres, todo lo cual haría factible la ampliación del universo cronológico incorporando a nuestro estudio sitios precerámicos. Sin embargo, hasta ahora, esta aspiración no ha sido todavía conseguida. En el futuro pensamos integrar al registro arqueológico del proyecto, algunos restos de tradición incásica. Las actividades de laboratorio no estuvieron encaminadas a la clasificación de los restos pero las observaciones preliminares nos permiten apercibir ya algunas tradiciones culturales antiguas:

a. Conjuntos tardios.- Los sectores noroccidentales del Azuay presentan una característica utilería correspondiente al denominado Período de 
Integración (500 - 1450 d.C.), que estudiosos anteriores denominaron "Cashaloma", homónimo estilístico de un conocido yacimiento de la vecina provincia de Cañar. Los fragmentos recolectados en Chillohuay, cerca de Sinincay, nos permiten reconocer las formas y patrones ornamentales típicos de esta tradición:

- Grandes recipientes cerrados, globulares, con un diámetro de abertura de 25 - $40 \mathrm{~cm}$., cuello de dirección oblicuo-externa y forma ligeramente cóncava. Las paredes corporales tienen un promedial espesor de 1,5 cm. y los labios son notoriamente engrosados. Este tipo de recipientes comporta variedades subtipológicas tanto en el borde, que en su perfil presenta a veces un falso corrugado, como en su remate, la sección labial, en donde frecuentemente se exagera el engrosamiento de su sección exterior presentando un aspecto ribeteado.

- Recipientes abiertos con un diámetro de abertura de $20 \mathrm{~cm}$. y $2 \mathrm{~cm}$. de alto (platos) con un ligero engrosamiento labial, cuyo borde dispone de una orientación oblicuo-interna y de forma convexa. El espesor del fondo tiene un centímetro. En ambos casos el tratamiento de superficie comprende engobes cremas y pintura roja exterior que, a manera de franja horizontal, cubre el labio y la sección exterior del borde. La pasta de los tiestos, rojiza y bien cocida, ha sido atemperada con arena fina.

Al suroriente de la provincia están igualmente representados estos tipos cerámicos aunque el alto índice de erosión de los tiestos no ha permitido la conservación de la decoración pintada; la prospección de esta misma zona sobre los espolones que dominan Nabón, nos ha permitido distinguir que es la cultura "Tacalzhapa", topónimo de un sitio azuayo situado al nororiente de la provincia, la que presenta, igual que en la oriental zona de Sígsig, la más elevada frecuencia cerámica. Así, gruesos fragmentos de compoteras y numerosos pies de recipientes polípodos suponen un poblamiento tardío suplementario devenido posiblemente desde la floresta amazónica. Los restos de tradición Cashaloma, en cambio, parecen pertenecer a una evolución cultural operada desde épocas anteriores en la propia comarca.

El extremo septentrional de la provincia (Saucay), el suroccidente de la misma y el valle del río Paute a la altura de Guachapala, nos han permitido recolectar muestras pertenecientes al período de Desarrollo Regional (500 
a.C. - 500 d.C.), período que difuminó la decoración de pintura blanca sobre rojo a partir de "Tuncahuán", de la provincia de Chimborazo. Las formas cerámicas, el espesor y las técnicas complementarias de ornamentación están igualmente relacionadas con el lapso histórico señalado. Estos tipos han sido localizados además en las inmediaciones de los ríos Santa Bárbara y San Francisco, en Gualaceo. Los labios pintados de rojo y engrosados exteriormente, la utilización de abundante mica como desgrasante de una pasta de buena cocción y la visible evolución morfológica proveniente de un grupo anterior común, están también relacionados con el período en mención.

b. Posibles conjuntos tempranos.- Únicamente en dos sectores ha sido posible localizar tiestos de posible tradición formativa. En la terraza aluvial del Paute, cerca de Guachapala, parece estar representada la misma tradición alfarera que Bennett denomina "Chaullabamba". La extraordinaria finura de los fragmentos de las paredes de pequeños cuencos engobados y cocidos en atmósfera reductora, nos posibilita vislumbrar este período (2000 - 500 a.C.).

La otra zona que presenta presumibles restos formativos es el valle bajo del río Chico, en Zhumiral. Este grupo de tiestos proviene de estratos ubicados a una profundidad de tres metros promediales; los lavadores de oro en este río, en el transcurso de sus roturaciones, han hecho aflorar fragmentos de una utilería probablemente vinculada con los estilos generales, que abarcan muchas variedades, denominados "Narrío Rojo sobre Color Ante" y "Cañar Pulido" por Collier y Murra, para designar a los grupos cerámicos más antiguos de Cañar. La pintura roja de estos cerámicos tiene lustre por alisamiento o pulimentación; así, los pequeños recipientes cerrados de muy corto cuello de dirección oblicuo-externa, ligeramente cóncavo, labio redondo y diámetro de abertura de $20 \mathrm{~cm}$., están representados en algunos fragmentos de la muestra. Existen también recipientes abiertos característicos de estos estilos y la profusión ornamental incluye círculos blancos en negativo de una franja horizontal obscura, dibujos púrpuras sobre rojo lustroso, alusiones geométricas pintadas, etc. El espesor de los tiestos es de $0,5 \mathrm{~cm}$., y la cocción es indistintamente mala o buena; el desgrasante preferencial es arena aurífera muy fina. No hay que olvidar que los trabajos de la misión francesa en Loja, reportan restos formativos similares en el valle del Catamayo. 
Para concluir, debemos hacer una observación complementaria: Parece que, salvando el mejor criterio, una tradición cúltica intensamente relacionada con la cabeza humana cubre buena parte de la historia cultural del sur andino del Ecuador. La mayoría de los fragmentos recolectados, incluso los coloniales, presentan retoques y pequeñas excisiones, sugerentes de la silueta humana. Este interés aparentemente ritual se concreta en el retoque de otros materiales: Huesos de animales, conchas, madera, y posiblemente en mayor densidad, en numerosos materiales líticos. 


\section{REFERENCIAS BIBLIOGRAFICAS}

ACOSTA Solís,M.

1968, Divisiones fitogeográficas y formaciones geobotánicas del Ecuador. Casa de la Cultura Ecuatoriana, Quito.

ALMEIDA Duran, N.

1975, en colaboración con Mario Jaramillo P., Juan Martínez B. y Manuel Agustín Landivar U. Diario de Campo. Comisión de Todos Santos, Cuenca, manuscrito inédito.

1978, Relación de los objetos arqueológicos localizados por los investigadores de la Comisión de Ingapirca Napoleón Almeida y Jaime Idrovo durante las excavaciones en la quebrada del Intihuayco desde diciembre de 1975 hasta diciembre de 1976. Comisión del Castillo de Ingapirca, Cuenca, manuscrito inédito.

1980, Informe sobre el catálogo del sitio Todos Santos, Cuenca, manuscrito inédito.

1981 ${ }^{a}$, en colaboración con Ángel Montes del Castillo, Pucará: informe arqueológico. En Revista Pucará número 4, Revista de la Facultad de Filosofía, pp. 96-111, Universidad de Cuenca, Cuenca.

1981b, Las tribus históricas de la provincia de Loja, colaboración para la edición del 8 de septiembre de diario El Mundo, p. 4, Loja.

1982a, El periodo de Integración en el sur de la provincia de Loja. En Boletín del Instituto Francés de Estudios Andinos, Tomo XI, número 3-4, pp. 29-37, Lima. (Este articulo se reprodujo en "Cultura", revista del Banco Central, edición monográfica dedicada a la provincia de Loja, Vol. V, número 15 -enero abril 1983- pp. 89-97, Quito). 
1982b, Los "zarzas", grupo cultural tardio del sur de Loja. Tesis previa al titulo de doctor en historia y geografía, 168 pp. 30 tablas, 21 planchas, 1 anexo, Facultad de Filosofia y Letras, Universidad de Cuenca, Cuenca, manuscrito inédito.

1983a, La phase Zarza. Texto remitido al editor, París.

1983b, La fase Zarza. Texto remitido al editor, París.

1984, Les "zarzas", un groupe culturel tardif du Sud de la province de Loja, en Equateur. Tesis para la obtención del título de doctor en etnología prehistórica, 225 pp., 30 tablas, 19 planchas, 1 anexo, Universidad de París 1 (Panteón Sorbona), manuscrito inédito.

BENNETT, W.

1946, Excavations in the Cuenca Región, Ecuador. Yale University n. 35, New Haven.

BUCHARD, J. F.

1983, Programme Tumaco. En Rapport Scientifique 1980-1983 de I'URA n. 25 du CNRS, pp. 32-45, París.

COLLIER, D. y John Murra

1943, Survey and excavations in Southern Ecuador, Chicago.

DOLLFUS, O.

1978, Les Andes Centrales Tropicales vues par deux géographes:

Isaiah Bowman et Cari Troll. En Boletín del Instituto Francés de Estudios Andinos, T. VII, n. 3-4, pp. 7-21, Ed. Stella, Bogotá.

GUFFROY, J.

1981, Investigaciones arqueológicas en el Sur de la provincia de Loja. Publicaciones del Banco Central del Ecuador. Ed. Cosmos, Loja.

1983, Programme Loja. En Rapport Scientifique 1980-1983 de 1' URA n. 25 du CNRS, pp. 46-62, París. 
JARAMILLO P., M.

1976, Estudio Histórico sobre Ingapirca. Centro de publicaciones Pontificia Universidad Católica del Ecuador, Quito.

JIJON y Caamaño, J.

1941, El Ecuador interandino y occidental antes de la conquista castellana. 4 ts., Quito; t.1, 1941; t.2, 1943; t.3, 1945; t.4, 1947.

LAVALLEE, D.

1977, Projet de recherche archéologique dans les Andes équatoriennes. CNRS, URA n. 25 (Préhistoire des régions andines), 4 pp., manuscrito, Paris.

-- y Michèle Julien

1983, Programme Junín. En Rapport Scientifique 1980 - 1983 de 1'URA n. $25 d u$ CNRS, pp. 15- 31, Paris.

MURRA, J.

1975, (1972), El control vertical de un máximo de pisos ecológicos en la economía de las sociedades andinas. En formaciones Económicas y Políticas del mundo andino, pp. 59-115, Instituto de Estudios Peruanos, Lima.

MEGGERS, B.

1965, Ecuador. Thames and Hudson.

PORRAS G., P.P. y Luis Piaña B.

1975, Ecuador Prehistórico. Imprenta y ediciones Lexigrama, Quito.

SALAZAR, E.

1980, Talleres prehistóricos en los Altos Andes del Ecuador. Publicaciones del Departamento de Difusión Cultural de la Universidad de Cuenca, Cuenca.

SALOMON, F.

1981, Los Señores Étnicos de Quito en la época de los Incas. Publicaciones del Instituto Otavaleño de Antropología, Col. Pendoneros, 10B, Otavalo.

UHLE, M.

1930, El Reino de Quito. Boletín de la Academia Nacional de Historia, Vol. 10, n. 27, pp. 1-17, Quito. 
La presente edición se terminó de imprimir en Julio de 1988 En el Departamento de Publicaciones de la Pontificia Universidad Católica del Ecuador, Sede en Cuenca
Diseño y Diagramación
Jaime Gómez Saldaña
Composición de Textos
Diana Matute Tapia
Impresión
Patricio Cáceres y
José Encalada

Tiraje: 1000 ejemplares 